\title{
Percepção de risco à contaminação por mercúrio em peixes em Macapá- Amapá
}

\section{Risk perception to contamination by mercury in fish in Macapá-Amapá}

\author{
Cecile de Souza Gama1, Gabriela Gama Jaster², Beatriz Emanuele Dias ${ }^{3}$, Eduardo Pinheiro ${ }^{4}$ \\ ${ }^{1}$ Bióloga, Doutora em Ciências Biológicas (Zoologia). Pesquisadora do Instituto de Pesquisas Científicas e Tecnológicas do Estado do Amapá - \\ IEPA. Macapá-AP Brasil.E-mail: cecilegama@hotmail.com *Autor para correspondência \\ ${ }^{2}$ Estudante da Escola Conexão Aquarela. Macapá-AP Brasil. E-mail: jastergabriela@gmail.com \\ ${ }^{3}$ Estudante da Escola Conexão Aquarela. Macapá-AP Brasil.E-mail: biaemanuele9@gmail.com
}

${ }^{4}$ Estudante da Escola Conexão Aquarela. Macapá-AP Brasil.E-mail: eduardongpinheiro@gmail.com

\section{Palavras-chave \\ Feira livre \\ Consumo de peixes \\ mercúrio}

\begin{abstract}
O presente estudo tem como objetivo analisar a percepção de risco à contaminação por mercúrio na população do município de Macapá, Amapá. A escolha do local para a realização de tal pesquisa se justifica pela contaminação por mercúrio elementar verificada em peixes de diferentes rios ao longo do Estado que fornece peixes às feiras de pescado. A metodologia partiu da aplicação de questionários estruturados em questões discursivas e objetivas, através de entrevistas individuais. Foram entrevistados 62 indivíduos entre consumidores e comerciantes do pescado em feiras localizadas no município de Macapá. Os resultados mostram que a grande maioria dos entrevistados possuem apenas informações desencontradas sobre o mercúrio e que em geral não sabem sobre suas propriedades ou os males que o mercúrio pode causar na saúde humana ou no ambiente. A falta de informação sobre o assunto foi percebida quando as pessoas respondiam sem demonstrar conhecimento ou certeza ou não demonstrando nenhuma preocupação a respeito.
\end{abstract}

This study aims to analyze the risk perception of mercury contamination in the population of Macapá, Amapá. The choice of the place to carry out such research is justified by the contamination by elementary mercury verified in fish from different rivers throughout the State that supplies fish to the fish markets. The methodology started from the application of structured questionnaires on discursive and objective questions, through individual interviews. 62 individuals were interviewed, including fish consumers and traders, at fairs located in the municipality of Macapá. The results show that the vast majority of respondents have only mismatched information about mercury and that in general they do not know about its properties or the dammages that mercury can cause in human health or the environment. The lack of information on the subject was noticed when people responded without showing knowledge or certainty or showing no concern about it.

\section{INTRODUÇÃO}

O mercúrio $(\mathrm{Hg})$ é um metal pesado tóxico capaz de causar envenamento agudo e principalmente crônico em pessoas com efeitos duradouros no sistema nervoso (WHO, 1991). Os efeitos causados podem ser danos cerebrais, diminuição da coordenação motora com alteração da fala e do andar, parestesia, ataxia, neurastenia, tremores, falta de equilíbrio, sensação de fraqueza, fadiga, dificuldade de concentração, diminuição do campo visual e da audição, além de outros efeitos, tais como a teratogenia, podendo levar até à morte (GOYER; CLARKSON 2001).

Esse metal representa grave ameaça à saúde humana por ser altamente bioacumulativo e provocar diversos efeitos nocivos à saúde (PASSOS; MERGLER, 2008, KEHRIG et al., 2010).
A extração do ouro com o uso não controlado do mercúrio nos processos de mineração acarreta sérios problemas de contaminação ambiental e de exposição humana (CARDOSO et al., 2014).

$\mathrm{Na}$ região amazônica, a utilização do mercúrio para amalgamar o ouro tornou-se comum, fazendo com que grandes quantidades deste metal pesado fossem liberadas para o ambiente (CASTILOS; RODRIGUES, 2008), sendo carreado pelos rios contaminados. Através dos processos de bioacumulação e biomagnificação, o mercúrio é retido pelos peixes em seus tecidos e já está bem estabelecido que a principal forma de contaminação humana é através da ingestão desses peixes contaminados.

Para Barbosa et al. (2003), a pesca na região amazônica é a principal fonte nutricional para as populações que vivem as margens dos rios. Em comparação às demais regiões 
brasileiras, tanto costeiras quanto de águas interiores, há maior riqueza de espécies de peixes exploradas, maior quantidade de pescado capturado e maior dependência da população tradicional a atividade pesqueira (SOARES et al., 2016).

Os peixes carnívoros estão no topo da cadeia alimentar e acumulam maiores níveis (LIMA et al., 2015), sendo por isso utilizados como bioindicadores da contaminação por mercúrio. Em regiões onde existe um alto consumo de peixes, como na Amazônia, o potencial de exposição humana ao mercúrio através da alimentação é maior.

De acordo com White (1985, apud SOUZA; ZANELA, 2009) o significado da expressão "percepção de risco" é o processo pela qual os riscos são subjetivamente ou intuitivamente, entendidos e avaliados. Faz- se importante tomar conhecimento da percepção do risco da população, sendo possível então a partir de tal análise propor atividades de estímulo e reflexão sobre tais problemas ambientais. Para Slovic e Weber (2001) a percepção de risco desempenha um papel importante na decisão que as pessoas tomam e as diferenças nessa percepção se encontram no centro das divergências sobre as ações dos técnicos e da população em geral. Tuan (1980) defende que para os riscos terem sentido e possam ser "percebidos" pelos indivíduos é necessário fazer com que os mesmos tenham uma participação mais crítica perante tais situações, possibilitando a compreensão desses processos, que na maioria das vezes são muito complexos para a população leiga. Oliveira e Machado (2007) ressaltam que só percebemos aquilo nos tem significado. Dessa maneira os desenvolvimentos de estudos relacionados à percepção podem auxiliar na elaboração de estratégias de comunicação, de educação ambiental e de participação popular, fazendo com que os riscos passem a ter sentido para o indivíduo.

O estudo teve como objetivo analisar a percepção de risco da contaminação por mercúrio na população de Macapá que consome ou comercializa o pescado em feiras de Macapá.

\section{MATERIAL E MÉTODOS}

A metodologia aplicada nesta pesquisa foi a elaboração de questionários norteadores aplicados preferencialmente em duas grandes feiras de comercialização de pescado no município de Macapá (AP) durante o mês de abril e maio de 2019. Foram entrevistados consumidores do pescado e comerciantes, escolhidos aleatoriamente, nas feiras de pescado do Buritizal e do Igarapé das Mulheres além de consumidores que não se encontravam-nas feiras. Nos questionários constavam perguntas objetivas relacionadas à sua condição social e subjetivas relativas a questão pesqueira com o objetivo de não induzir o entrevistado a uma resposta.

\section{RESULTADOS E DISCUSSÃO}

Foram entrevistadas 62 pessoas, sendo 27 na feira de pescado do Buritizal, 24 pessoas na feira de pescado do Igarapé das Mulheres e 11 pessoas de locais aleatórios fora das feiras. $48 \%$ dos entrevistados foram do sexo masculino e 52 do sexo feminino e destes, 15 eram vendedores e 47 consumidores.

Com relação à idade dos entrevistados, a maior parte (47\%) tinha acima de 30 anos de idade, no entanto foram entrevistadas pessoas com idade mínima de 12 anos e máxima de 73 anos.

Quando os entrevistados foram perguntados se sabiam o que era o mercúrio, 58\% afirmaram saber do que se tratava, no entanto, eles poderiam enquadrar o mercúrio em mais de uma categoria. Dessa forma, dos que afirmaram que sabiam do que se tratava o mercúrio, $32 \%$ afirmaram se tratar de um metal, $22 \%$ de um produto químico e $7 \%$ de um mineral. Apenas $15 \%$ afirmaram que era um produto, material ou metal utilizado em garimpos de ouro.

Além do seu uso em garimpos o mercúrio também é utilizado no processo de fabricação de defensivos agrícolas, na indústria de cloro-soda, na indústria eletro-eletrônica para a fabricação de lâmpadas fluorescentes e baterias, na indústria de tintas e outras indústrias químicas (LACERDA, 1997). No entanto a maioria da população desconhece sua participação nesses processos.

Além do citado, ainda foram apresentadas outras atribuições ao termo mercúrio, como planeta, remédio (tintura antisséptica), veneno, produto tóxico, elemento radioativo ou produto usado em vacinas, como respostas aleatórias e imprecisas. Dessa forma, observamos que apesar de alguns terem respondido corretamente, não tinham muita certeza do que estavam falando.

Os entrevistados que responderam corretamente sobre o que seria o mercúrio, tinham na sua maioria, idade entre 41 e 50 anos, mostrando que eles adquiriram alguma sabedoria sobre o assunto ao longo do tempo.

Foi perguntado se os entrevistados sabiam que o mercúrio poderia causar algum dano à saúde das pessoas e $42 \%$ afirmaram que sim, o mercúrio era prejudicial à saúde ou ao ambiente. Logo, 58\% não sabiam que o mercúrio poderia fazer algum mal à sua saúde. Sobre os males do mercúrio, as pessoas podiam também dar mais de uma resposta e a maior parte dos entrevistados (29\%) respondeu que o mercúrio causa doenças, mas não sabia especificar quais. Outros afirmaram que o mercúrio podia causar câncer (13\%), contaminação (20\%), morte de pessoas (7\%) e morte de peixes (10\%), poluição da água. Irritação da pele, problemas 
de vista, etc.

Quando foi perguntado aos entrevistados se eles sabiam que os peixes poderiam conter ou estar contaminados com o mercúrio, $79 \%$ afirmaram que tinham conhecimento sobre o assunto, no entanto, destes, $63 \%$ afirmaram saber onde o mercúrio se acumulava nos peixes e o restante, apesar de dizer que os peixes podiam estar contaminados, não sabiam afirmar onde essa contaminação se acumulava. Muitos disseram que o mercúrio se encontrava nas vísceras e que por isso não tinha tanto problema no consumo, apesar de já ser comprovado que o músculo é a estrutura que mais acumula mercúrio quando comparado a outros órgãos nos peixes (CARDOSO et al., 2009).

Os entrevistados foram perguntados se, em caso de contaminação por mercúrio, eles saberiam dizer como essa contaminação chega às pessoas. $52 \%$ afirmaram saber como as pessoas podem se contaminar e eles também puderam indicar mais de uma fonte de contaminação. Assim, a maioria dos entrevistados indicou os hábitos alimentares como a principal fonte de contaminação por mercúrio, seja por alimentos em geral (24\%) ou pela ingestão de peixes (37\%). A ingestão de água contaminada também foi uma fonte de contaminação muito indicada (34\%). Então, a maioria dos entrevistados acertou essa pergunta.

Dentre os entrevistados, $97 \%$ disseram não ter como saber se os peixes adquiridos ou pescados encontram-se contaminados. O restante, $3 \%$ disseram que os peixes malconservados podem estar contaminados. Os peixes contaminados por mercúrio não apresentam características específicas ou sintomas que indiquem a sua contaminação, não sendo, dessa forma, possível evitar o consumo de peixes contaminados.

Com relação à origem do peixe comercializado, 37\% afirmaram se preocupar com a origem do peixe que está comprando ou vendendo, mas apenas $5 \%$ afirma ter certeza de que o peixe em questão não se encontra contaminado com mercúrio. Mais uma vez, como não é possível verificar a contaminação dos peixes por mercúrio sem análise em laboratório, também não é possível se certificar visualmente acerca da presença ou não de mercúrio no pescado em feiras livres.

Os entrevistados foram perguntados se eles sabiam se, uma vez contaminados, os peixes ou o ambiente poderiam ser recuperados. Apenas $26 \%$ afirmaram ser possível a recuperação, no entanto não sabiam como fazer para tal. 0 pescado pode ser submetido a alguns processamentos com o intuito de eliminar o mercúrio da amostra, que envolve o uso de algumas substâncias como cisteína após trituração do músculo e aquecimento (OKAZAKI et al., 1984, MORALESAIZPURÚA et al., 1997), ou a imersão do músculo em água com $\mathrm{NaCl}$, porém, com baixa eliminação (FERNANDÉZ-SOLIS et al., 1976). Cohen e Schrier (1975) propuseram o uso de Borohidreto de Sódio $(\mathrm{NaBH} 4)$ para separação mecânica de Mercúrio em proteína de peixe. Em todos os casos, as tentativas de remoção da contaminação de mercúrio foram feitas através do processamento do pescado e não com o peixe inteiro, como são encontrados em feiras livres.

Os consumidores apresentam preferências por determinadas espécies de peixes. Quando perguntados, eles poderiam informar mais de uma espécie preferida. 0 peixe mais citado foi o filhote, seguido da dourada, pirapitinga, tambaqui e pescada. Alguns entrevistados (11 indivíduos) afirmaram não possuir preferência por alguma espécie de peixe (Figura 1).

Figura 1. Espécies de peixes preferenciais citadas pelos entrevistados.

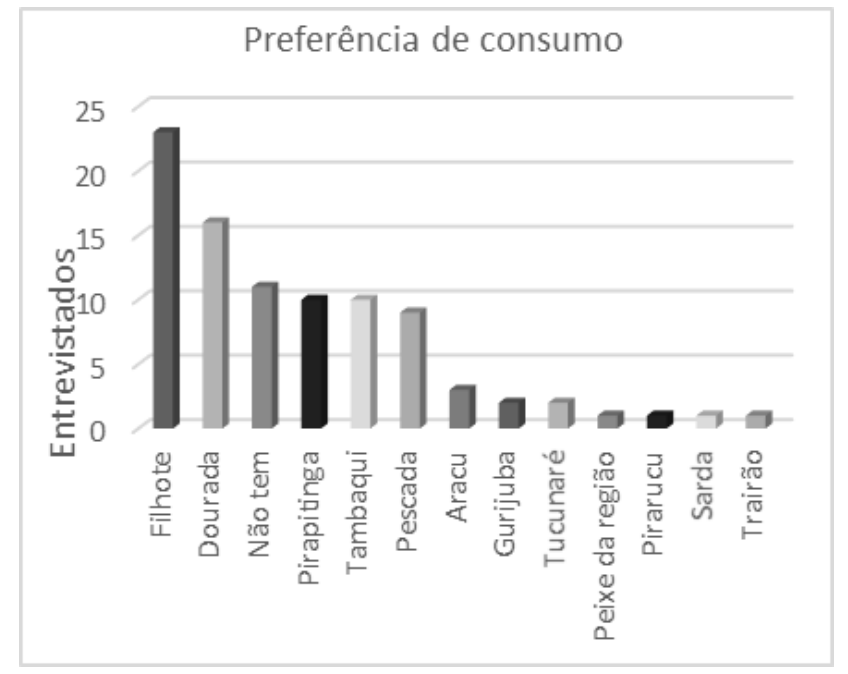

Com relação ao consumo de peixes entre os entrevistados, a maioria afirmou consumir pescado duas vezes por semana, a frequência de consumo não segue um padrão, contudo, a grande maioria dos entrevistados afirmou fazer consumo de peixes de forma regular (Figura 2). Os entrevistados que afirmaram não consumir peixes se trataram de vendedores.

Já é bem sabido que os peixes carnívoros são os que apresentam maior contaminação por mercúrio (LIMA et al., 2015) e por isso, o consumo de peixes predadores (planctívoro, carnívoro/piscívoro e carnívoro/necrófago), segundo Beltran-Pedreros et al. (2011), devem ser evitadas. No entanto, segundo estes autores, os peixes com hábito alimentar: detritívoro, herbívoro/frutívoro e onívoro, que possuem baixas concentrações de $\mathrm{Hg}$, em alguns locais são mais frequentemente consumidas pela população.

O grande consumo de peixes também é um fator que deixa as pessoas mais predispostas a se contaminarem caso consumam peixes contaminados (PEREIRA; YALLOUZ, 2004), como observado por Hightower e Moore (2003) que encontraram correlação positiva entre o consumo de peixe e 
o aumento da contaminação de mercúrio em pessoas por eles acompanhadas.

Figura 2. Frequência de consumo de peixes pelos entrevistados.

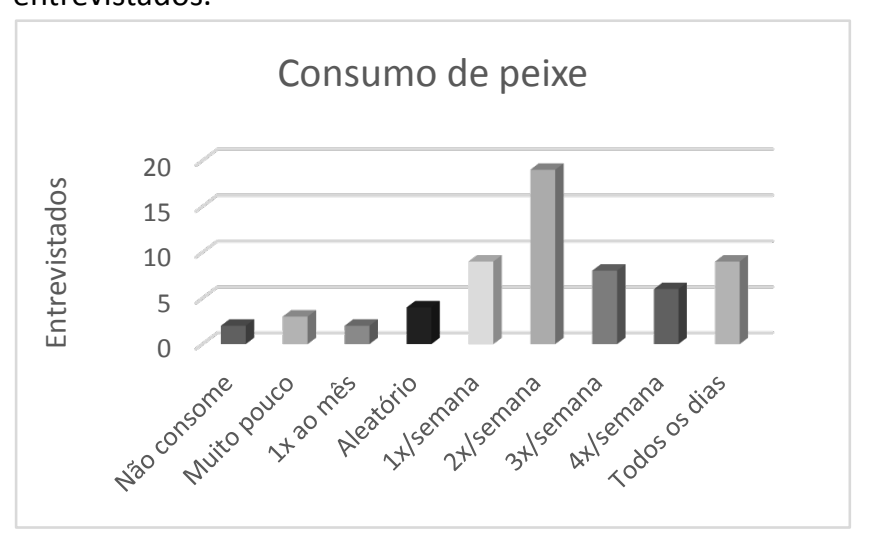

Em um estudo realizado em um hospital de São Francisco, Califórnia ondes os testes de níveis de contaminação por mercúrio eram feitos constantemente, verificou-se que quando os pacientes se abstinham de peixes, seus altos níves corporais de mercúrio diminuíam com facilidade, mas era necessário um período mínimo de 21 semanas sem o consumo de peixe (HIGHTOWER; MOORE, 2003).

\section{CONCLUSÃO}

Pelas entrevistas pudemos verificar que a população não tem muita certeza sobre o problema do mercúrio dos peixes. Alguns têm uma noção ou já ouviram falar, mas não percebem que o problema é sério e merece atenção.

A contaminação de mercúrio nos peixes, apesar de ser preocupante a nível mundial parece não causar preocupação nas pessoas que consomem o pescado em Macapá.

Concluímos que as pessoas não percebem que existe o risco de contaminação por mercúrio durante o consumo de peixes.

\section{REFERÊNCIAS}

BARBOSA, A. C.; SOUZA, J.; DO'REA, J. G.; JARDIM, W.F.; FADINI, P. S. Mercury Biomagnification in a Tropical Black Water, Rio Negro, Brazil. Archives of Environmental Contamination and Toxicology, v. 45, p. 235-246, 2003.

BELTRAN-PEDREROS, S.; ZUANON, J.; ROSSEVAL GALDINO LEITE, R. G.; PELEJA, J. R. P.; MENDONÇA, A. B.; FORSBERG, B. R. Mercury bioaccumulation in fish of commercial importance from diferente trophic categories in an Amazon floodplain lake. Neotropical Ichthyology, v.9, n. 4, p. 901-908, 2011.

CARDOSO, N. A.; HOSHINO, A. C. H.; PEREZ, M. A.; BASTOS, W.
R.; CARVALHO, D .P.; CÂMARA, V. M. Zumbido em uma população ribeirinha exposta ao metilmercúrio. Audiol Commun Res., v. 19, n. 1, 40-4.2014.

CARDOSO, T. P.; MÁRSICO, E. T.; MEDEIROS, R. J.; TORTELLY, R.; SOBREIRO, L. G. Concentração de mercúrio e análise histopatológica em músculo, rim e cérebro de peixeespada (Trichiurus lepturus) coletados na praia de Itaipu, Niterói, Rio de Janeiro, Brasil. Ciência Rural, v. 39, n. 2, p. 540-546. 2009.

CASTILHOS, Z. C.; RODRIGUES, A. P. C. Avaliação da Potencial Acumulação de Mercúrio em Peixes dos Reservatórios (previstos) de Jirau e de Santo Antônio, Rio Madeira, RO. CETEM/MCT. SÉRIE ESTUDOS E DOCUMENTOS. 105p. 2008.

COHEN, G. B.; SCHRIER, E. E. Removal of Mercury from fish protein concentrate by sodium borohydride reduction. Journal of Agricultural and Food Chemistry. Washington, v. 23, n. 4, p. 661-665. 1975.

FERNÁNDEZ-SOLÍS, J. M.; MARTÍNEZ, F. B.; CAPONT, F. L.; LAMAS, M. L. R. Reducción del nível de mercúrio em conservas de atún mediante tratamentos com cisteína. Revista de Agroquímica y Tecnología de Alimentos, Valencia, v. 16, n. 2, p. 273-278. 1976.

GOYER, R. A.; CLARKSON, T. W. Toxic effects of metals. In: Klaassen, C. D., editor. Casarett and Doull's toxicology: the basic science of poisons. 6a. ed. New York: McGraw-Hill;. p. 834-7. 2001.

HIGHTOWER, J. M.; MOORE, D. Mercury Levels in High-End Consumers of Fish. Environmental Health Perspectives, v. 111, n. 4, p. 604-608. 2003.

KEHRIG, H. A.; SEIXAS, T. G.; BAÊTA, A. P.; MALM, O.; MOREIRA, I. Inorganic and methylmercury: do they transfer along a tropical coastal food web? Mar Pollut Bull., v. 60, n. 12, p. 2350-6. 2010.

LACERDA, L. D. Contaminação por mercúrio no Brasil: fontes industriais vs garimpo de ouro. Química Nova, v. 20, n. 2, p. 196-199. 1997.

LIMA, D. P.; SANTOS, C.; SILVA, R. S., YOSHIOKA, E. T. O.; BEZERRA, R. M. Contaminação por metais pesados em peixes e água da bacia do rio Cassiporé, Estado do Amapá, Brasil. Acta Amazonica, v. 45, n. 4, p. 405 - 414. 2015.

MORALES-AIZPURÚA, I. C. M.; TENUTA-FILHO, A.; SAKUMA, A. M.; ZENEBON, O. Use of cysteine to remove mercury from shark muscle. International Journal of Food Science and Technology, Oxford, v. 32, n. 4, p. 333-337. 1997.

OKAZAKI, E.; KANNA, K.; SUZUKI, T.; KIKUCHI, T. Elimination of mercury from shark flesh. Tokai-ku Suisian Kenkyusho Kenkyu Hokoku, Tokay, v. 114, p. 125-132. 1984.

OLIVEIRA, E.; MACHADO, K. S. Adaptações curriculares: caminho para uma educação inclusiva in: GLAT, R., (org). Educação inclusiva: cultura e cotidiano escolar. Rio de 
Janeiro: 7 Letras, 2007.

PASSOS, C. J.; MERGLER D. Human mercury exposure and adverse health effects in the Amazon: a review. Cad Saúde Pública., v. 24 (Suppl 4), p. 503-520. 2008

PEREIRA, D.; YALLOUZ, A. V. Recicladora artesanal de lâmpadas fluorescentes: estudo de caso do potencial de aplicação de método alternativo de determinação de mercúrio In: JORNADA INTERNA CIENTÍFICA, Rio de Janeiro: Centro de Tecnologia Mineral, 2004. 1 CD-ROM.

SLOVIC, P.; FISCHOFF, B.; LICHTENSTEIN, S. Facts and fears: under-standing perceived risk. In: SLOVIC, P., (ed.) The Perception of Risk. London: Earthscan, 137-154. 2000.

SOARES, J. L. F.; GOCH, Y. G. F.; PELEJA, J. R. P.; FORSBERG, B. R.; LEMOS, E. J. S.; SOUSA, O. P. Bioacumulação de Mercúrio Total ( $\mathrm{Hg}$ ) e hábitos alimentares de peixes da bacia do Rio Negro, Amazônia, Brasil. Biota Amazônia, v. 6, n. $1, \quad$ p. $102-106.2016 . \quad$ DOI: http://dx.doi.org/10.18561/2179-

5746/biotaamazonia.v6n1p102-106

TUAN, YI-FU. Topofilia: um estudo da percepção, atitudes e valores do meio ambiente. São Paulo: Difel, 1980.

VENTURIERI, R.; COSTA, M. O., GAMA, C.S., JASTER, C. B. Mercury Contamination within Protected Areas in the Brazilian Northern Amazon-Amapá State. American Journal of Environmental Sciences, v. 13, p. 11-21. 2017.

WHO. Environmental Health Criteria (EHC 101). Methylmercury. Geneva,. 143p. 1990.

WHO. Inorganic mercury. World Health Organization, Geneva. 1991.

ZANELLA, L. Metodologia de estudo e de pesquisa em administração. Brasília: CAPES. 2009. 